\title{
Q.
}

ISSN 2278 - 0211 (Online)

\section{A Report on Maiduguri Hand Embroidered Cap Stock Exchange}

\author{
Ashiedu Peter Ogboli \\ Faculty of Arts, Department of Visual and Performing Arts, University of Maiduguri, Nigeria
}

\begin{abstract}
:
The former Alkome Clinic junction and bus stop at Ahmadu Bello Way by Monday Market, Maiduguri, Borno State, is currently the centre of a thriving hand embroidered cap stock exchange. It is strategically located and connects all parts of Maiduguri in a single bus or taxi ride. A large quantity of handmade caps is traded there daily. Prices are set depending on the volume of trade, the quality of the product, and several other factors, including seasonal festivities, cash flow among the brokers and patrons.This paper reports on the study, which involves hundreds of male and female participants. A daily average census is made, while an estimate of the cash value if the commodity is also studied. Young women predominates the design area of the trade, while males predominate as brokers. The professional training and other relevant information are derived from the study. The study also aims to highlight the state of affairs in these viable vocations, and hopes to generate additional scholarly work that could help government and other stake holders; optimally tap into its potentials and similar initiatives.
\end{abstract}

Keywords: Designers, stock exchange, stock broker, market forces, professional training

\section{Introduction}

This study is based on the researcher's observation in mid-2013, that quiet but consistent pattern of embroidered cap business interchange is going on in Maiduguri. The nature of the cap stock exchange business is such that it could go unnoticed by several segments of society; who would thereby be unable to make as much contribution as they could/ or and should to the community. This is in line with the suggestion of Waziri (2012). The study therefore sought to carefully verify and document the significance of this viable trade network, in order to properly position it in the first place; and to thereafter, suggest how it can be carried forward to the benefit of all the parties concerned. Earlier studies have identified Bomb state as the most important maker and market for hand embroidered caps in Nigeria (Ogboli 2004 and 2010).

The researcher's attention was initially drawn to the activities of the interchange when he observed participants who usually converge daily by the former Alkome Clinic junction on Ahmadu Bello Way, by Monday Market. This study started in Maiduguri toward the middle of 2013. The period was marked by economic uncertainty and serious security challenges for Maiduguri. As the study progressed, it was revealed that the activities observed at Alkorne Clinic junction interchange, was just a fraction of an elaborate network that draws in thousands of participants; and in which a large volume of materials in form of embroidered caps are traded for huge sums of money.

The resources available to the researcher, the time frame allotted for the study, and other constraints of research, prompted the study to be limited to the immediate vicinity of the Alkome interchange, at Alkome Clinic junction. Although highlights on its linkages with the operations of other associates inside Monday Market, which is its real nexus is made here. This researcher observes that there are at least two other ongoing embroidered cap stockexchanges in Maiduguri. They are to be found at Bulabulin Ward, Au Kotoko Area, Maiduguri, where their trade specializes in Tangaram and other caps from Bama, which are interconnected with the Alkome Clinic area stock exchange. There is also a third cap stock exchange at London Ciki Ward, which mainly handles caps embroidered by women residents of Maiduguri. These two other embroidered cap stock exchanges are outside the scope of this paper, and are therefore not discussed in any detail here.

\section{Research Questions}

Research questions are as follows:

- Where is the cap stock exchange located?

- What is its modus operandi?

- Who are the designers and other stake holders or participants?

- What are the estimated average earnings of the participants? 
- What benefit is there for individuals, government and other stake holders? (vi) Finally, how can the trade be carried forward?

\section{Methodology}

On the spot observation, participant observation, interviews and written transcripts in response to a questionnaire were collated in order to reach the findings. This study is set against a backdrop of serious security constraints that restrict movement, economic and documentation activities, such as cinematography and photography, without due clearance, and especially in open areas. A questionnaire in Hausa language comprising about twenty key questions were administered on respondents. Incidentally, most of the participants are apparently not Hausa by origin, although a majority is proficient in that tongue. Therefore Hausa was the main language of interaction, with occasional interjections in Kanuri, Arabic or English. The cap stock exchange has a hierarchy which apparently functions effectively. The leadership of the cap traders was identified at various levels and the researcher satisfactorily identified himself and explained his mission in more than eight different visits. A little honorarium was arranged for guides, facilitators and respondents. Census figures of participants and the value of goods traded are only estimates, since audited figures were unavailable. Heavy reliance was put on the interview method and participant observations, since they tended to work better and faster than questionnaires, especially outside academic settings. Information gathered was cross-checked with the respondents. The study started in June, 2013 and lasted till end of May, 2014. It will hopefully form part of a larger study of a similar subject matter.

\section{Observations}

"Zawa" is the name that the Kanuri call the cap trade. The cap trade by nature is a quiet vocation. Its main users are men. Being hand-made, a hand embroidered cap cannot usually be finished in one day. It requires the input of several individuals, often specializing in a particular aspect or stage, and in cooperation with several other persons, for the common goal of making a profit from the commodity. It is in that wise, a complex trade. It is sometimes subtle, rhythmic, relying on a consistency in order to function. Many of the handlers of atypical cap are anonymous. This study identified up to twelve handlers, in the process of finishing and selling a cap. The minimum number of individuals is four. Even when a direct commission from an end-user or patron is made, the handlers would usually not be less than four individuals.

Therefore, understanding the cap interchange could throw more light on the subtleties of society and how some of its facets work, away from the harsh gaze of observers. The cap interchange also helps consolidate several social mores. It is notew orthy that up to fifty percent of all embroidered caps reaching the market are handled at some or all stages by females. Sociologists and economists can explain how and why women have apparently risen to fill this niche. They may also be able to tell us how we can harness this female participation for more gender empowerment and economic growth, In order to make and sell one Zanna Bukar cap, (also called or Haji or Kube) at least ten individuals are involved in the process chain. Typically it would start with the seller of the khaki, raft or canvas cloth, then the designer of the draft pattern; then its seller. Next would be the retailer of the threads and accessories used during the embroidery. The accessories include needles, thimbles, razor blades and other miscellaneous items. From this point, the embroiderer will enter the draft pattern unto the cloth surface, after which it would be bought by a stock broker who would sell it to a dealer. Thereafter, a retailer would buy it from the dealer, and take it toa seamstress or tailor to join the inner landing, the top and the crown together. Then it would be washed, starched, beaten or pressed for a sheen and package for the shop window display. In this manner, there are sometimes up to a dozen or more beneficiaries along the way.

\section{The Former Alkome Clinic Junction Cap Stock Exchange}

The exchange is made up of about seventy members or participants, who gather on a daily basis in order to trade on various aspects of the embroidered cap.

Although the membership is exclusively male, females participate in the market. Their participation is mainly as embroiderers or sellers of embroidered goods, presumably made by them, or gathered from their friends and associates. The females may also wield some influence in the setting of prices, the choice of design and the colours of threads and their combination. The exchange opens at about 9:00am every morning and runs until about 4:30pm in the evening. During this time, the traders huddle together, or stroll around in search for potential sellers of embroidered caps. The traders' intention is to buy the cap at a bargain price, then resell it at a slightly higher price in order to make a profit. They therefore seldom display their goods from shops, but rather carry it on their person or in bags. They often serve as agents for the big-time dealers and retailers who own shop spaces within Monday Market Maiduguri. Most of them enter the trade informally; having served or still serving as under-studies in trading and "Almajirai"; as they would describe themselves assimple folk, or students undergoing Qur'anic education. The participants are mainly youths of later teens to mid-thirties.

The female embroiderers are often teenagers, young housewives, widows, or sedentary women, who are able to find time to carry on the obvious tedium and monotony of stitchery for long periods; until all the design patterns are correctly entered unto the baft, canvas or khaki material. These kind women of could be observed stitching the caps in buses, in hospital waiting rooms, underneath shade trees, or during break times, away from menial jobs in government and private offices. The caps can be sold at any point of the stitchery. What is accomplished already is assessed, a bargain is struck, and the embroiderer is paid off. In this wise, the embroidery craft provides a kind of guaranteed legal tender. A woman coining for shopping, may arrive Monday Market without cash at hand, sell off her cap or caps and use the money realized to make her 
purchases. In this wise, she has direct control over her own earnings, unlike perhaps earnings from the sale of farm produce. The average cap sold by female embroiderers costs about two thousand naira as at March, 2014. By 2018 the median cost has increased to four thousand naira, due to various reasons including inflation and the devaluation of the naira. This is a median cost. Some caps cost up to twenty Thousand Naira when first finished, while a greater proportion; up to fifty percent (50\%) cost about One Thousand Five Hundred Naira. The baft or canvas backing cloth costs about Two Hundred Naira, while the assorted threads cost about Five Hundred Naira. Therefore, the typical embroiderer earns just about a Thousand Naira for the lowest grade of embroidered caps, which represents about three weeks of stitchery, to which about five hours is devoted daily. It is not easy to know the number of stitches it takes to fill in an average cap.

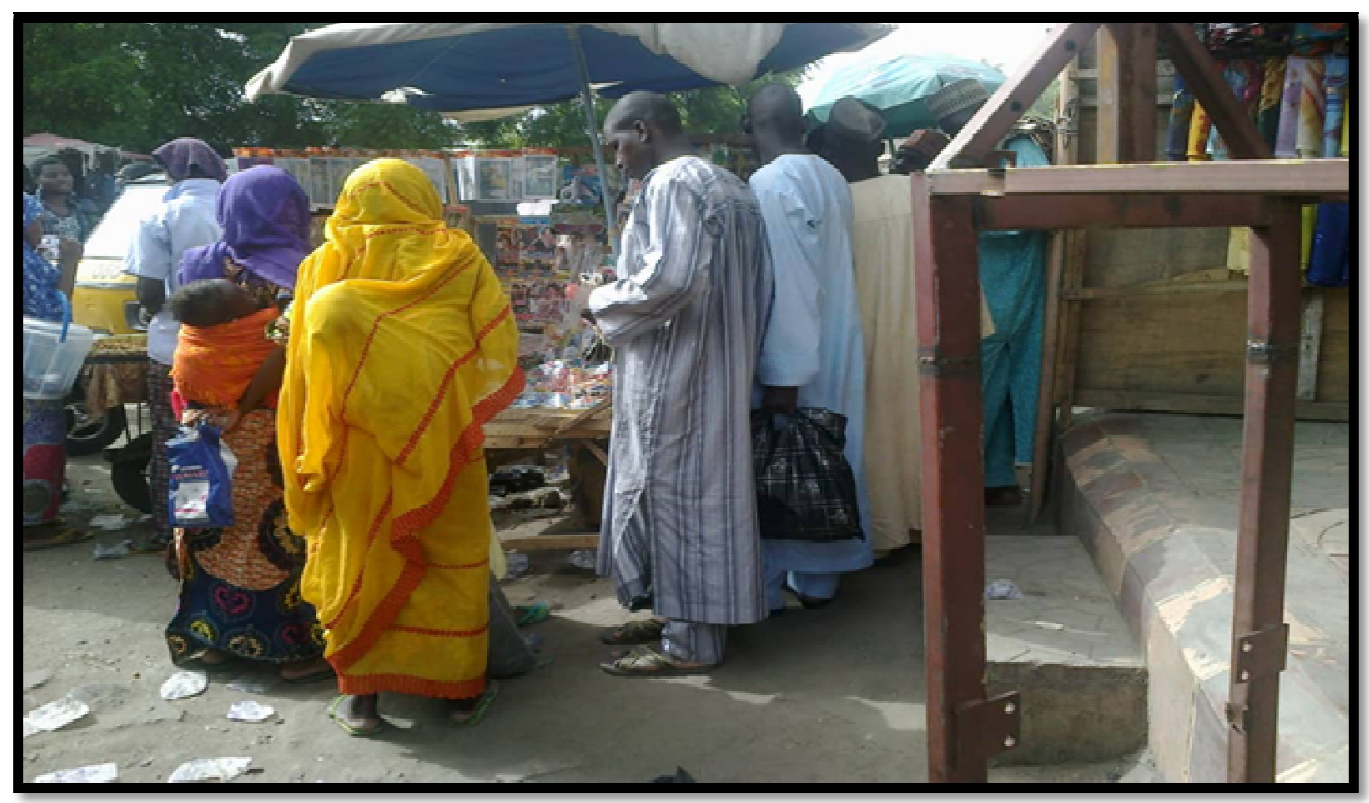

Figure 1: Designers (Females) and Hand Embroidered Cap Brokers (Males) Discuss and Transact Their Business at Alkome Hospital Junction, Monday Market Maiduguri, Nigeria. Picture Taken by the Author in 2014

A fair guess is that between ten and twenty thousand stitches are required, depending on the complexity which often determines the eventual worth - of the embroidered cap. The high-end caps (which may cost up to Eighteen Thousand Nairaat first asking), are seldom sold or bought at Alkome Clinic cap stock exchange. The main reason is that the traders there are predominantly small-time brokers, without the back-up of a huge cash layout. In such an instance, a broker would take it to a bigger dealer (in A9 Area) inside Monday Market. A broker may also join forces with his colleagues in order to make such an expensive purchase. Most of the Alkome area brokers work as independents, and are only in loose association with their neighbors. Such an association may not have any deep financial implication beyond mere proximity and sameness of occupation. The vast majority of respondents are pressed for space, operational capital, a conducive operating environment. A vast majority of the brokers are satisfied with the quality of the products reaching them, and depend on market forces to judge. Although they are aware of trade fairs directories, and fashion fairs, a vast majority of them do not have the know-how to benefit from these, in another respect, their unions and association may not have the legal framework and expertise to organize these activities in a way that may be more reflective of the twenty first century.

In times of difficulties, or in order to meet certain unforeseen needs, levies and donations are taken from members, who seem to have a high level of confidence on their leadership hierarchy.

Up to $70 \%$ of respondents have between three and twenty five thousand naira as their trading capital. Seldom do they have more than twenty five thousand naira trading capital. They do not operate thrift and saving cooperatives of any note. Most of the respondents are indigenes of Borno State. Their caps come from Maiduguri Metropolitan Council and environs, Bama Town, Gwoza, Chad and Cameroon. Dealers take the products to places as varied as the republic of Benin, Cote'dIvoire, Saudi Arabia, USA and Europe. Alhaji Bamma and Goni Umar (2014) estimate that up to ten thousand units of hand embroidered cap are traded in the A9 Maiduguri Monday Market cap trading systems on a daily basis. If we assume that the average cost of a cap is two thousand five hundred naira, we can thenestimate the value of the daily trade at Twenty Million Naira, which goes on seven days a week and thirty days per month. This business can therefore earn 600 Million Naira per month. This will be the sum in excess of Seven Billion Naira in value per year. We can hereby begin to see the significance of this trade in financial terms and what it means for all the stake holders, both within the formal and the informal economy. The study observed that telephony is a veritable tool for price negotiation and other business activities. On another note, the stock brokers working in leagues, agree loosely on what the prices should be, and tend to abide by the agreements. They thereby ensure that the prices are kept stable, affordable, and that their profit margins are good. A lucky trade could result in a trader 
gaining as much as a $100 \%$ on a particular cap. The study did not delve into the ethics of such a relatively high profit margin. But traders may have rational and tenable explanations for such occurrences.

The Alkome Clinic junction cap stock exchange accounts for more than $10 \%$ of all hand embroidered caps traded in Maiduguri. This means that the market value is over six hundred million naira per annum.

\section{Recommendations}

The following recommendations are hereby made:

That the exact percentage of the trade in terms of volume and financial value of the Alkome Clinic/ Monday Market junction cap stock exchange should be established through further research, since it is part of a wider trade network.

Since Borno State is the most important maker and market for hand embroidered caps in Nigeria, its total economic worth should be ascertained through further investigation.

Two other cap stock exchange markets were identified in the course of the study. This researcher recently learnt of the existence of another cap stock exchange at Tashan Baga, in Maiduguri and other parts of Bomo State. Studies should be carried out to locate, document and bring them into the mainstream of Nigeria's socioeconomic focus.

This study revealed that a majority of the stock brokers are small-time traders, who have little trading capital, and are in hardship to access Joan facilities, in addition to trading under the harsh exposure to the elements. Almost all of them are without their own office, storage or shop space. Government should urgently try to liaise with their unions, in order to ameliorate their difficulties. The practical benefits can make iteasier for trading, census, accounting, security, tax collection among other myriad benefits.

The academic community of University of Maiduguri, can arrange with the stakeholders; which include the following; the designers, the embroiderers, the marketers, their associations and unions, agencies of Borno State government, such as the Council for Arts and Culture, the Ministry of Commerce and Trade, Youth organizations in other to arrange a regular calendar of trade fairs, exhibitions, galas and promotional activities via the mass media, trade brochures, catalogues, etcetera. The Internet as a viable medium of information and trade enhancement should be carried out to find out how and why women became "suddenly" predominant in cap embroidery. Are they for instance victims of social instability, refugees, displaced windows, job seekers, school leavers or whatever? Also what special needs do they have? One could go as far as to say that, in the face of dwindling natural resources, large scale unemployment, disguised underdevelopment, this hand craft industry could be parleyed into a putative escape route for the teeming masses. Better organization of the skills, quality and marketing bases of the professi6n can buttress it, and harness it for regional empowerment and national pride. In this regard, examples of Persian rug making in countries like Iran, Afghanistan, Uzbekistan, Pakistan and elsewhere can be taken.

Bangladesh. Vietnam, Cambodia, Indonesia and Malaysia are countries that have recognized human beings and their artistry as great national resources and are repositioning themselves appropriately as developing economies. What this paper is proposing already exists, but needs much enhancement within the organized system. The problem and prospects of Borne State are apparently predominantly grass roots issues (Waziri, 2012). Individuals, families, wards, local communities, local and the state government should come up with practicable and viable solutions.

\section{References}

i. Bamma, Alhaji and Umar Goni (2014). Interviewed in February and March, A9 Monday Market, Maiduguri, Borno State.

ii. Ogboli, A.P. (2004) Master and Acolytes: Hand Embroidered Caps in Maiduguri and Environs. Borno Museum Society BMS (Journal) No.58 and 59.

iii. Ogboli, A. P. (2011). Another Look at Hand Embroidered Caps in Bama and Maiduguri Cultural Centre Calabar, Cross River, Nigeria. Paper presented at 2nd SNA and International Convention on Art and Development (CONADEV) September.

iv. Ogboli, A. P. (2012). Ergonomics as an Option for Repackaging Old Design Ideas. A Paper Presented at Alexander Von Humboldt Kolleg International Conference on Socio - Economic Sustainability of Livelihood in the Lake Chad Basin. Hosted by University of Maiduguri/ DRACC, Lugbe II, Abuja, Nigeria. December 11-13

v. Waziri, I., M.(2012). The Lake Chad Basin As a Historical Socio-Economic Platform ofRelationships and Livelihood for the Peoples in the Region. A Plenary Paper Presented at Alexander Von Humboldt Kolleg International Conference on the Socio-Economic sustainability of livelihood in the Lake Chad Basin. University of Maiduguri DRACC, Lugbe II, Abuja, Nigeria. December 11-13.

vi. Waziri, I, .M. (2012). Integrated Documentation of Physical and Human Dynamics: AStrategy for Managing Development in the Lake Chad Basin. A PaperPresented at Alexander Von Humboldt Kolleg International Conference on the Socio-Economic Sustainability of livelihood in the Lake Chad Basin. Hosted by University of Maiduguri at DRACC, Lugbe II, Abuja, Nigeria. December,11-13.

vii. Waziri Mohammed et. al., (2009) Issues in the Geography of Bomo State. Vol. Adamu Joji Publishers, No. 123 Mangwarori Street, Sabon Titin Mandawari Kano City, Kano State, Nigeria 


\section{Acknowledgement}

I am grateful to the Cap Marketers Association of Monday Market Maiduguri; to the Chairman Alhaji Goni Umar, A9 Monday Market Maiduguri, Aihaji Muhammed Umar Bamma, Vice Chairman, A9 Monday Market Maiduguri, Goni Mukhtari, A9 Monday Market Maiduguri, who gave me relevant information on the trade. I wish to also thank Mallam Bashir Mafoni, Monday Market Maiduguri for his time/ information and Mallam

Abubakar Mohammed Abuja, cap brokers at Alkome Junction Ahmadu Bello Way,Maiduguri for facilitating the study. Thank you very much. 